\title{
Constructing and Validating an Occupational Mechanical Job Exposure Index (MJEI) Based on Five Norwegian Nationwide Survey of Living Conditions on Work Environment
}

Åsmund Hermansen ( $\sim$ asmuhe@oslomet.no )

OsloMet - Oslo Metropolitan University

Espen Dahl

OsloMet - Oslo Metropolitan University

Research Article

Keywords: index, exposures, work, validation

Posted Date: January 20th, 2022

DOI: https://doi.org/10.21203/rs.3.rs-1195338/v1

License: (a) (1) This work is licensed under a Creative Commons Attribution 4.0 International License. Read Full License 


\section{Abstract}

Background: The aim of this study is to (i) construct and validate a job exposure index for mechanical job exposures and (ii) test its predictive validity for individual reported lower back pain and long-term sick absence, as well as disability benefits, long-term sick leave and mortality using register data.

Methods: We utilize data from the Norwegian nationwide Survey of Living Conditions on work environment in 2006, 2009, 2013, 2016 and 2019. Occupations are classified on a 4-digit level based on the Norwegian version of the International Standard Classification of Occupations (ISCO-88). We constructed a 4-digit correspondence table between the occupational codes used in the 2006 and 2009 surveys (STYRK-98) and the codes used in 2013, 2016 and 2019 (STYRK-08). The mechanical exposures were collected by Statistics Norway using telephone interviews. We validate the agreement between the individual- and occupationalbased mechanical exposure index (MJEI) estimates using Spearman`s Rho, sensitivity and specificity measures. The predictive validity of the mechanical job exposure matrix was tested investigating the association between individual reported lower back pain and long-term sick absence and the individual- and MJEl estimates. Furthermore, we investigate the association between disability benefits, mortality and the number of long-term sick absence periods, retrieved from register data, and the occupational-based mechanical exposure (MJEI) estimates.

Results: The analysis shows a fair-to-moderate overlap between occupational-based mechanical exposure index (MJEI) and the index based on individual reported exposures. When assessing the predictive value of the occupational-based mechanical exposure index to the index based on the individual reported exposures, the MJEl showed lower and reproducible associations with lower back pain for both men and women. For long-term sick leave, the MJEl showed higher and reproducible associations for both genders. As for the register-based outcomes, the MJEl predicts disability and a significant higher number of long-term sickness benefits periods for both men and women. For men the MJEI also predicts higher mortality.

Conclusion: The predictive value of the mechanical job exposure index (MJEI) is overall acceptable and will be useful in registerbased studies lacking information on these types of exposures.

\section{Introduction}

The Nordic countries have a longstanding tradition of using high quality register data for research purposes. The fact that these data often include the entire population and consists of long time series makes them "a goldmine" for research (1). However, these data are not collected for research purposes and therefore often lack information that is vital for research into social inequalities in health and epidemiological register research in general. Varying dimensions of working conditions are usually such a "missing piece of the jigsaw puzzle" in register-based research. Knowledge about work environment is crucial in itself in a democratic society that cares about the population's living conditions and well-being. In addition, knowledge about the pathways into and out of employment and different types of jobs is important to assess the interrelationship between work, health and wellbeing over the life course $(2 ; 3)$. One way to overcome the problem of missing information on work environment in register data is to use a job exposure matrix (JEM). Based on job titles JEM's have been developed for a number of different and specific exposures and stressors $(4 ; 5 ; 6)$. Despite the great advantage of creating this kind of information for use in register data, a notorious problem with JEM is that it entails the risk of misclassification which limits its applicability. This relates to the exact definition of exposures as well as the definition of exposed/non-exposed. These possibilities and challenges related to JEM are the motivation for this undertaking.

In Norway, Hanvold et. al. (7) have constructed a JEM for mechanical and psychosocial job exposures based on the Norwegian nationwide Survey of Living Conditions on work environment in 2006 and 2009. This paper is inspired by the innovative work done by these researchers. We have, however, moved beyond Hanvold et al. in two ways. First, we have added three Norwegian nationwide Survey of Living Conditions on work environment, i.e. for the years 2013, 2016 and 2019. Hence we have achieved a much larger number of observations. Second, we have applied JEM on Norwegian register data and investigated the associations between JEM and three health outcomes, disability benefits, mortality, and the number of long-term sick absence periods.

\section{Previous Research}


Use of nation-wide and longitudinal register data for research purposes has many advantages (1). One challenge though is the lack of information on exposures to job hazards of different types (4). One solution to these problems is to use a Job Exposure Matrix (JEM). A JEM is used to assign exposures on the basis of occupational titles. Hence, a JEM is potentially convenient when information on individual occupation is available, but there is no information on job exposures or job hazards, as is the case in Norwegian register data. The JEM method is quite extensively used and has proved useful in several contexts $(6 ; 8 ; 9)$. As indicated JEMs have been produced to capture several types of exposures and stressors, such as biological, mechanical, chemical and psychosocial. Since our JEM addresses mechanical exposures only, we will primarily review empirical studies that have assessed the reliability and validity of mechanical JEMs.

In the Netherlands Rijs et al. (10) found that use of force and work in uncomfortable positions were significantly associated with functional limitations and self-perceived health. A moderate probability of repetitive movements was associated with functional limitations in former workers. A high probability of repetitive movements was associated with functional limitations in current and former workers as well as with SPH and hip and knee. The authors conclude that the results suggest that the JEM accurately classifies jobs according to physical demands.

In Finland Solovieva et al. (5) reported that the specificity of the mechanical JEM was, in particular among women. The degrees of agreement, measured by kappa, were fair for most exposures. For men, all JEM exposures were significantly associated with one month prevalence of low back pain. For women, this applied to four out of six JEM exposures. The researchers conclude that the JEM can be «considered as a valid instrument for exposure assessment in large-scale epidemiological studies, when more precise but more labour-intensive methods are not feasible» (5: $\mathrm{p}$ 1).

In Norway Hanvold et al. (7) constructed and validated JEMs capturing mechanical as well as psychosocial work exposures. They found a general fair to moderate agreement between the JEM and individual work exposures. The JEM performed better for mechanical work exposures than for psychosocial stressors. The predictive validity of the mechanical JEM showed an acceptable relationship with the risk of low-back pain. The authors conclude that JEM «may be useful in large epidemiological register studies» (7: 239).

Against this background, the aim of this article is to propose a mechanical JEM for use in Norwegian register data. This implies to assess its statistical properties in various ways, as described below. The idea is to use this JEM for different purposes in our «research program» on work, health and welfare trajectories among vulnerable groups. Hitherto, available information in Norwegian register data has been limited to occupation (job titles), social class and employment status. Our ambition is to add a reliable and validated index variable describing mechanical exposures to this list. Specifically, we will construct a composite mechanical job exposure index (MJEI), compromising eight different mechanical job exposures, and validate it by the assessment of a confirmative factor analysis, by investigating the correspondence between the individual reported exposures and the occupational exposures, by judging sensitivity and specificity measures, and lastly by examining whether the MJEl predicts self-reported lower-back pain and long-term sick leave using survey data, and disability and long-term sick leave using register data.

Study population

The populations included in the analysis are described according to age, educational level and major occupational groups in Table 1 - the survey data and Table 2 - the register data. As shown in Table 1 the total population based on the survey data includes 43 977 individuals and the population based on the register data includes 1589535 individuals. The survey population includes all those who participated in the 2006, 2009, 2013, 2016 and 2019 Norwegian nationwide Survey of Living Conditions on work environment and had a valid occupational code. The high number of observations achieved by using respondents in five surveys is likely to increase the precision of the JEM estimates (11). The register data population includes all those who were between 18 and 55 years of age in 2007 and had a valid occupational code. 
Table 1

Background characteristics of the study population (survey data)

\begin{tabular}{|c|c|c|c|c|c|c|}
\hline \multirow[b]{2}{*}{ Age (years) } & \multicolumn{2}{|c|}{$\begin{array}{l}\text { All } \\
(\mathrm{N}=43977)\end{array}$} & \multicolumn{2}{|c|}{$\begin{array}{l}\text { Men } \\
(\mathrm{N}=23 \text { 062) }\end{array}$} & \multicolumn{2}{|c|}{$\begin{array}{l}\text { Women } \\
(\mathrm{N}=20915)\end{array}$} \\
\hline & $\mathrm{N}$ & $\%$ & $\mathrm{~N}$ & $\%$ & $\mathrm{~N}$ & $\%$ \\
\hline $17-24$ & 4484 & 10,2 & 2308 & 10,0 & 2176 & 10,4 \\
\hline $25-44$ & 19160 & 43,6 & 9880 & 42,8 & 9280 & 44,4 \\
\hline $45-69$ & 20333 & 46,2 & 10874 & 47,2 & 9459 & 45,2 \\
\hline Educational level & $\mathrm{N}$ & $\%$ & $\mathrm{~N}$ & $\%$ & $\mathrm{~N}$ & $\%$ \\
\hline Primary school & 11116 & 25,3 & 5979 & 25,9 & 5137 & 24,6 \\
\hline Secondary/High school & 14007 & 31,9 & 8524 & 37,0 & 5483 & 26,2 \\
\hline College/university 4 years & 13328 & 30,3 & 5508 & 24,9 & 7820 & 37,4 \\
\hline College/university $>4$ years & 5366 & 12,2 & 2969 & 12,9 & 2397 & 11,5 \\
\hline Major occupational groups (STYRK-98) & $\mathrm{N}$ & $\%$ & $\mathrm{~N}$ & $\%$ & $\mathrm{~N}$ & $\%$ \\
\hline Legislator, senior officials, and mangers & 4569 & 10,4 & 3032 & 13,1 & 1537 & 7,4 \\
\hline Professionals & 7921 & 18,0 & 4170 & 18,1 & 3751 & 17,9 \\
\hline Technicians and associate professionals & 11818 & 26,9 & 5236 & 22,7 & 6582 & 31,5 \\
\hline Clerks & 2743 & 6,2 & 1100 & 4,8 & 1643 & 7,9 \\
\hline Service workers, shop, and market sales workers & 8480 & 19,3 & 2514 & 10,9 & 5966 & 28,5 \\
\hline Skilled agricultural and fishery workers & 822 & 1,9 & 670 & 2,9 & 152 & 0,7 \\
\hline Craft and related trade workers & 3911 & 8,9 & 3665 & 15,9 & 246 & 1,2 \\
\hline Plant and machine operators and assemblers & 2552 & 5,8 & 2235 & 9,7 & 317 & 1,5 \\
\hline Elementary occupations & 1161 & 2,6 & 440 & 1,9 & 721 & 3,5 \\
\hline Low-back pain (previous month) & $\mathrm{N}$ & $\%$ & $\mathrm{~N}$ & $\%$ & $\mathrm{~N}$ & $\%$ \\
\hline Severely/somewhat & 5069 & 11,5 & 2245 & 9,7 & 2824 & 13,5 \\
\hline A little/not at all & 38908 & 88,5 & 20817 & 90,3 & 18091 & 86,5 \\
\hline Long-term sick leave (previous month) & $\mathrm{N}$ & $\%$ & $\mathrm{~N}$ & $\%$ & $\mathrm{~N}$ & $\%$ \\
\hline Yes & 7046 & 16,0 & 2946 & 12,8 & 4100 & 19,6 \\
\hline No & 36931 & 84,0 & 20116 & 87,2 & 16815 & 80,4 \\
\hline
\end{tabular}


Table 2

Background characteristics of the study population (register data)

\begin{tabular}{|c|c|c|c|c|c|c|}
\hline \multirow[b]{2}{*}{ Age (years) } & \multicolumn{2}{|c|}{$\begin{array}{l}\text { All } \\
(N=1589535)\end{array}$} & \multicolumn{2}{|c|}{$\begin{array}{l}\text { Men } \\
(\mathrm{N}=819 \text { 232) }\end{array}$} & \multicolumn{2}{|c|}{$\begin{array}{l}\text { Women } \\
(\mathrm{N}=770 \text { 303) }\end{array}$} \\
\hline & $\mathrm{N}$ & $\%$ & $\mathrm{~N}$ & $\%$ & $\mathrm{~N}$ & $\%$ \\
\hline $18-24$ & 221568 & 13,9 & 113520 & 13,9 & 108048 & 14,0 \\
\hline $25-44$ & 903754 & 56,9 & 472831 & 57,7 & 430923 & 55,9 \\
\hline $45-55$ & 464213 & 29,2 & 232881 & 28,4 & 231332 & 30,0 \\
\hline Educational level & $\mathrm{N}$ & $\%$ & $\mathrm{~N}$ & $\%$ & $\mathrm{~N}$ & $\%$ \\
\hline Primary school & 321207 & 20,2 & 176392 & 21,5 & 144815 & 18,8 \\
\hline Secondary/High school & 714616 & 45,0 & 399202 & 48,7 & 315414 & 41,0 \\
\hline College/university 4 years & 424436 & 26,7 & 167405 & 20,4 & 257031 & 33,4 \\
\hline College/university $>4$ years & 117827 & 7,4 & 70469 & 8,6 & 47358 & 6,2 \\
\hline Major occupational groups (STYRK-98) & $\mathrm{N}$ & $\%$ & $\mathrm{~N}$ & $\%$ & $\mathrm{~N}$ & $\%$ \\
\hline Legislator, senior officials, and mangers & 174674 & 11,0 & 93566 & 11,4 & 81108 & 10,5 \\
\hline Professionals & 188963 & 12,0 & 101577 & 12,4 & 87386 & 11,3 \\
\hline Technicians and associate professionals & 326718 & 20,6 & 147123 & 18,0 & 179595 & 23,3 \\
\hline Clerks & 125183 & 7,9 & 50160 & 6,1 & 75023 & 9,7 \\
\hline Service workers, shop, and market sales workers & 383242 & 24,1 & 111858 & 13,6 & 271384 & 35,2 \\
\hline Skilled agricultural and fishery workers & 9810 & 0,6 & 7176 & 0,9 & 2634 & 0,3 \\
\hline Craft and related trade workers & 170450 & 10,7 & 161664 & 19,7 & 8786 & 1,1 \\
\hline Plant and machine operators and assemblers & 127104 & 8,0 & 107531 & 13,1 & 19573 & 2,5 \\
\hline Elementary occupations & 83391 & 5,24 & 38577 & 4,7 & 44814 & 5,8 \\
\hline Disability benefits (2008-2017) & $\mathrm{N}$ & $\%$ & $\mathrm{~N}$ & $\%$ & $\mathrm{~N}$ & $\%$ \\
\hline Yes & 4878 & 0,31 & 1939 & 0,24 & 2939 & 0,38 \\
\hline No & 1584657 & 99,69 & 817293 & 99,76 & 767364 & 99,62 \\
\hline Mortality (2008-2017) & $\mathrm{N}$ & $\%$ & $\mathrm{~N}$ & $\%$ & $\mathrm{~N}$ & $\%$ \\
\hline Dead & 18467 & 1,16 & 11484 & 1,4 & 6983 & 0,91 \\
\hline Not dead & 157068 & 98,84 & 807748 & 98,60 & 763320 & 99,09 \\
\hline Ten long-term sick leave periods or more (2008-2015) & $\mathrm{N}$ & $\%$ & $\mathrm{~N}$ & $\%$ & $\mathrm{~N}$ & $\%$ \\
\hline \multicolumn{7}{|l|}{ Yes } \\
\hline No & & & & & & \\
\hline
\end{tabular}

The construction of the job exposure matrix (JEM)

The job exposure matrix, which forms the foundation for the Mechanical Job Exposure Index (MJEI), was developed by Hanvold et. al. (7) as a gender-specific matrix with group-based exposure estimates at each intersection between the occupations (rows) and the eight mechanical exposures (columns). To achieve reliable estimates, Hanvold et. al. decided to have at least $\geqslant 19$ respondents with the same occupational code when constructing the JEM groups. They report that two of the authors grouped the occupations and discussed further with a third author and two experts at the Norwegian Institute of Occupational Health. In total they 
constructed 268 JEM-groups based on occupational codes and the answers from 18939 respondents in the 2006 and 2009 surveys. The job exposure matrix we used when constructing the MJEl is identical to the matrix developed by Hanvold et. al. except from the fact that we also included the 2013, 2016 and the 2019 Norwegian nationwide Survey of Living Conditions on work environment. Inclusion of these three survey populations increased the total $\mathrm{N}$ with 25037 respondents and increased the mean number of respondents in each JEM group from 176 to 412. As shown in Table 3 the mean number of respondents per JEM group more than dobled in both men and woman.

Table 3

Number of occupational titles according to number of repsondents and number of respondents per JEM group

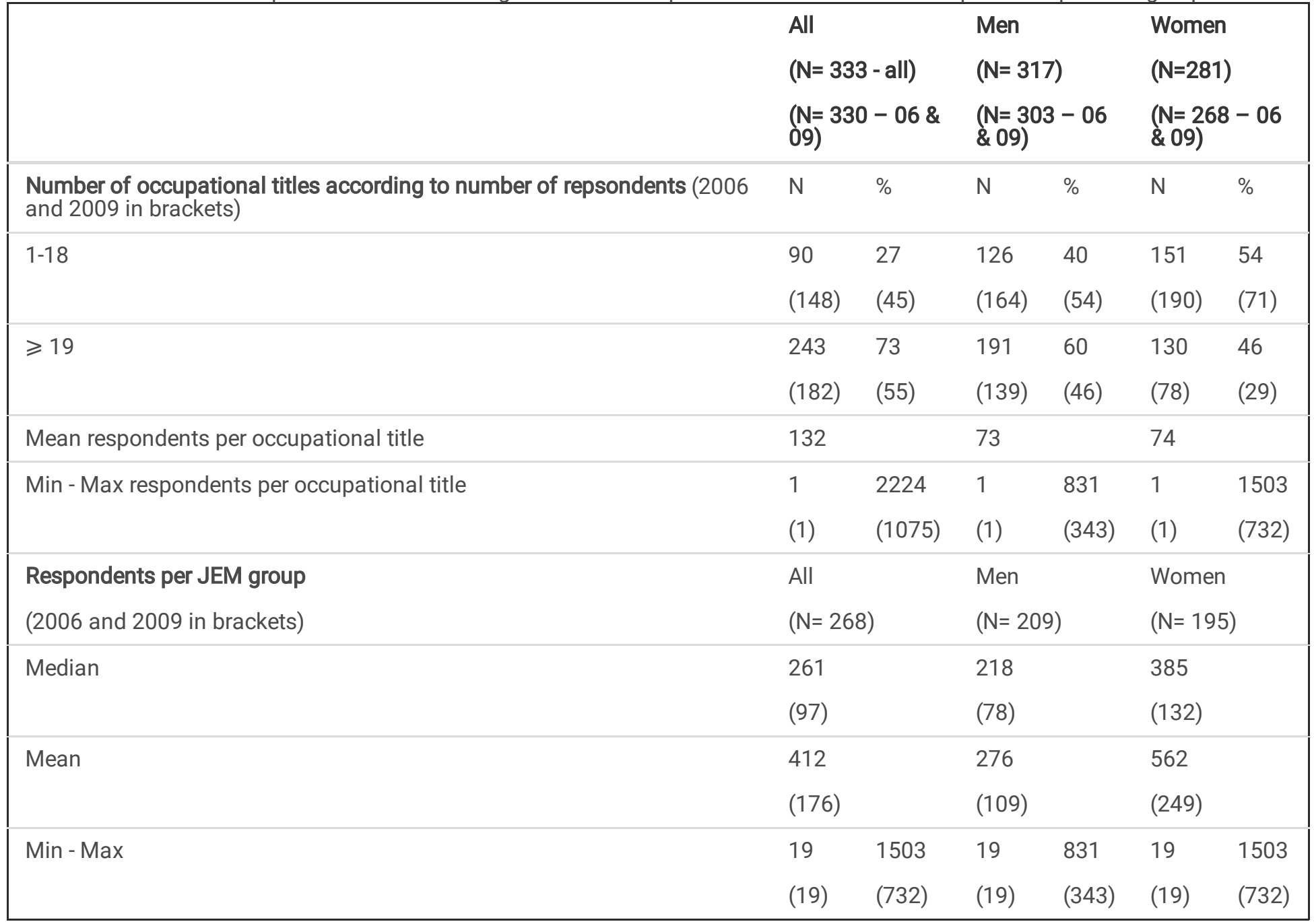

The 2006 and 2009 survey is not directly comparable to the 2013, 2016 and the 2019 in the sense that the two first surveys are based on 4-digit STYRK-98 occupational codes and the three later are based on 4-digit STYRK-08 codes. There is no official key of correspondence between the 4-digit STYRK-98 and the 4-digit STYRK-08 codes (confirmed in correspondence with Statistics Norway, section for labour market statistics), thus being able to append the five surveys we had to develop a key of correspondence. Since our register data includes the 4-digit STYRK-98 codes we choose to convert the 4-digit STYRK-08 codes in the 2013, 2016 and the 2019 survey into 4-digit STYRK-98 codes. When faced with the choice of having more than one STYRK-98 code to select, we chose to covert to the STYRK-98 code with the highest N in the 2006 and 2009 survey combined. This applied to 28 percent of the 4-digit STYRK-08 occupational codes, thus 72 percent remained unchanged.

Mechanical job exposures

The occupational-based mechanical exposure index is based on the same eight mechanical exposures Hanvold et.al. used when constructing their gender-specific job exposure matrix (JEM). The measures used for the self-reported mechanical exposures were developed by an expert group in a Nordic project (12) and based on the scientific literature (13), the eight mechanical exposures 
were dichotomized into exposed and not exposed at the individual level. The questions and cut-off values used are shown in Table 4 below.

Table 4

Exposures, Questions and Non-exposed/Exposed Composite Mechanical Job Exposure Index

\begin{tabular}{|c|c|c|}
\hline Exposures & Questions & $\begin{array}{l}\text { Not } \\
\text { exposed/Exposed }\end{array}$ \\
\hline \multirow[t]{2}{*}{$\begin{array}{l}\text { Heavy lifting }(>20 \\
\text { kg) }\end{array}$} & $\begin{array}{l}\text { Do you have to lift something that weighs more than } 20 \mathrm{~kg} \text { daily, and in the case } \\
\text { of how many times per. day? }\end{array}$ & $\begin{array}{l}0=\text { Not exposed } \\
(\mathrm{No})\end{array}$ \\
\hline & $\begin{array}{l}\text { "Yes, at least } 20 \text { times per. day", "Yes, 5-19 times per. day", "Yes, 1-4 times per } \\
\text { day", "No" }\end{array}$ & $\begin{array}{l}1=\text { Exposed }(\geq 1-4 \\
\text { times) }\end{array}$ \\
\hline $\begin{array}{l}\text { Hands above } \\
\text { shoulder height }\end{array}$ & $\begin{array}{l}\text { Do you work with your hands raised at shoulder height or higher? - "yes" or "no" } \\
\text { If "yes" - Can you estimate how much of the workday you do this? "almost all } \\
\text { the time", "about } 3 / 4 \text { of the time", "about half the time", "about } 1 / 4 \text { of the time", } \\
\text { "very little part of the time" }\end{array}$ & $\begin{array}{l}0=\text { Not exposed (no } \\
\text { or very little of the } \\
\text { workday), } \\
1=\text { Exposed ( } \geq 1 / 4 \\
\text { of the workday) }\end{array}$ \\
\hline $\begin{array}{l}\text { Heavy physical } \\
\text { work }\end{array}$ & $\begin{array}{l}\text { Do you work so hard that you breathe faster? - "yes" or "no" } \\
\text { If "yes" - Can you estimate how much of the workday you do this? "almost all } \\
\text { the time", "about } 3 / 4 \text { of the time", "about half the time", "about } 1 / 4 \text { of the time", } \\
\text { "very little part of the time" }\end{array}$ & $\begin{array}{l}0=\text { Not exposed (no } \\
\text { or very little of the } \\
\text { workday), } \\
1=\text { Exposed ( } \geq 1 / 4 \\
\text { of the workday) }\end{array}$ \\
\hline Neck flexion & $\begin{array}{l}\text { Do you work with your head forward bending? - "yes" or "no" } \\
\text { If "yes" - Can you estimate how much of the workday you do this? "almost all } \\
\text { the time", "about } 3 / 4 \text { of the time", "about half the time", "about } 1 / 4 \text { of the time", } \\
\text { "very little part of the time" }\end{array}$ & $\begin{array}{l}0=\text { Not exposed (no } \\
\text { or very little of the } \\
\text { workday), } \\
1=\text { Exposed ( } \geq 1 / 4 \\
\text { of the workday) }\end{array}$ \\
\hline Squatting/kneeling & $\begin{array}{l}\text { Do you have to squat or kneel when you work? - "yes" or "no" } \\
\text { If "yes" - Can you estimate how much of the workday you do this? "almost all } \\
\text { the time", "about } 3 / 4 \text { of the time", "about half the time", "about } 1 / 4 \text { of the time", } \\
\text { "very little part of the time" }\end{array}$ & $\begin{array}{l}0=\text { Not exposed (no } \\
\text { or very little of the } \\
\text { workday), } \\
1=\text { Exposed ( } \geq 1 / 4 \\
\text { of the workday) }\end{array}$ \\
\hline Forward bending & $\begin{array}{l}\text { Do you work in forward-leaning positions without supporting yourself with your } \\
\text { hands or arms? - "yes" or "no" } \\
\text { If "yes" - Can you estimate how much of the workday you do this? "almost all } \\
\text { the time", "about } 3 / 4 \text { of the time", "about half the time", "about } 1 / 4 \text { of the time", } \\
\text { "very little part of the time" }\end{array}$ & $\begin{array}{l}0=\text { Not exposed (no } \\
\text { or very little of the } \\
\text { workday), } \\
1=\text { Exposed ( } \geq 1 / 4 \\
\text { of the workday) }\end{array}$ \\
\hline Awkward lifting & $\begin{array}{l}\text { Do you have to lift in awkward positions? - "yes" or "no" } \\
\text { If "yes" - Can you estimate how much of the workday you do this? "almost all } \\
\text { the time", "about } 3 / 4 \text { of the time", "about half the time", "about } 1 / 4 \text { of the time", } \\
\text { "very little part of the time" }\end{array}$ & $\begin{array}{l}0=\text { Not exposed (no } \\
\text { or very little of the } \\
\text { workday), } \\
1=\text { Exposed ( } \geq 1 / 4 \\
\text { of the workday) }\end{array}$ \\
\hline Standing/walking & $\begin{array}{l}\text { Do you work standing or walking? - "yes" or "no" } \\
\text { If "yes" - Can you estimate how much of the workday you do this? "almost all } \\
\text { the time", "about } 3 / 4 \text { of the time", "about half the time", "about } 1 / 4 \text { of the time", } \\
\text { "very little part of the time" }\end{array}$ & $\begin{array}{l}0=\text { Not exposed } \\
\text { ( } \leq 1 / 4 \text { of the } \\
\text { workday), } \\
1=\text { Exposed ( } \geq 1 / 2 \\
\text { of the workday) }\end{array}$ \\
\hline
\end{tabular}

All the exposure variables are constructed as the proportion of individuals within each JEM-group that are exposed to the specific exposure. Thus, we have constructed variables that, in principle, goes from 0 to 100 percent based variables that are dichotomous (exposed $=1$, not exposed $=0$ ). This means that occupational codes with a value of 0 on one of the variables implies that none with these occupational codes, belonging to the same JEM-group, has provided an answer that involves exposure. In contrast, the value 100 means that all respondents with that occupational code, belonging to the same JEM-group, have provided an answer that involves exposure. In total, we have 323 unique occupational codes that are used when the index is merged to register data. 
In order to investigate the factorial validity of the occupational-based mechanical exposure index (MJEI), confirmatory factor analysis was performed. The CFA model was fitted in Stata v16 and for model estimation maximum likelihood was applied.

Model evaluation was based on chi-square tests for model fit and further model fit indices, including the root mean square error of approximation (RMSEA), the comparative fit index (CFI), the Tucker-Lewis index (TLI) and the standardised root mean square residual (SRMR). For model fit to be interpreted as 'acceptable', a RMSEA of $<0.05$ was considered a close fit, while a RMSEA and a SRMR of up to 0.08 were considered acceptable. Comparing the fit of a target model to the fit of an independent or null model, the CFI has a cut-off for good fit CFI of $\geqslant 0.90$. A TLI of 0.95 indicates the model of interest improves the fit by $95 \%$ relative to the null model, and the cut-off for good fit was sat at TLI $\geqslant 0.95$. Furthermore, the correlations of residuals to improve model fit when fitting the nine one-factor models were considered. Correlated residuals $<0.2$ were considered acceptable when fitting the model $(14 ; 15)$. Potential model adjustments were based on modification indices as provided in the Stata output using the 'estat gof, stats (all)' command. To obtain a clearer idea of the data and potential problematic items, a one-factor model was fitted to the data. To test whether modifications, in terms of correlated within factor residuals, led to significant model improvement, modification indices were obtained using the 'estat mindices' command in Stata.

Table 5

Confirmatory Factor Analysis and internal consistency (Cronbach`s alpha) Composite Mechanical Job Exposure Index (one-factor

\begin{tabular}{|c|c|c|c|c|c|c|c|}
\hline Cronbach`s alpha: 0.89 & $\mathrm{X}^{2}$ & $\mathbf{p}$ & RMSEA & CFI & TLI & SRMR & $\begin{array}{l}\text { Correlated } \\
\text { error }\end{array}$ \\
\hline Original & 124.37 & 0.000 & 0.171 & 0.914 & 0.871 & 0.048 & \\
\hline $\begin{array}{l}\text { Heavy lifting (>20 kg) with Hands above shoulder } \\
\text { height }\end{array}$ & \multirow[t]{7}{*}{9.72} & \multirow[t]{7}{*}{0.285} & \multirow[t]{7}{*}{0.028} & \multirow[t]{7}{*}{0.999} & \multirow[t]{7}{*}{0.996} & \multirow[t]{7}{*}{0.015} & .082 \\
\hline Heavy lifting (>20 kg) with Heavy physical work & & & & & & & .055 \\
\hline & & & & & & & .062 \\
\hline Heavy lifting (>20 kg) with Squatting/kneeling & & & & & & & 095 \\
\hline Hands above shoulder height with Awkward lifting & & & & & & & 001 \\
\hline Squatting/kneeling with Awkward lifting & & & & & & & 1001 \\
\hline Forward bending with Standing/walking & & & & & & & $.0 / 2$ \\
\hline Exposures & \multicolumn{4}{|c|}{ *Standarised factor loading } & \multicolumn{2}{|c|}{ Standard error } & \\
\hline Share exposed - Heavy lifting (>20 kg) & \multicolumn{4}{|l|}{.744} & \multicolumn{2}{|l|}{.030} & \\
\hline Share exposed - Hands above shoulder height & \multicolumn{4}{|l|}{.816} & \multicolumn{2}{|l|}{.023} & \\
\hline Share exposed - Heavy physical work & \multicolumn{3}{|l|}{.758} & & \multicolumn{2}{|l|}{.029} & \\
\hline Share exposed - Squatting/kneeling & \multicolumn{3}{|l|}{.838} & & \multicolumn{2}{|l|}{.021} & \\
\hline Share exposed - Forward bending & \multicolumn{3}{|l|}{.728} & & \multicolumn{2}{|l|}{.031} & \\
\hline Share exposed - Awkward lifting & \multicolumn{3}{|l|}{.862} & & \multicolumn{2}{|l|}{.019} & \\
\hline Share exposed - Standing/walking & \multicolumn{3}{|l|}{.762} & & \multicolumn{2}{|l|}{.028} & \\
\hline
\end{tabular}

The results from fitting a one-factor model is shown in Table 5. The "Original" row shows the results when fitting the MJEl with no cross-loadings and no correlated residuals. All factor loadings were high (i.e. >0.7; see column "Standardised factor loading" in Table 4).

When fitting the one-factor model, correlated residuals were sequentially added to respective models, which improved each model fit significantly. As shown in Table 4, a model fit with ten modifications gave a satisfying model fit. All the correlated residuals were $<0.2$. The MJEl showed good internal consistency with a Cronbach's alpha of 0.89 (see Table 5). 
In order to assess the MJEl performance we used four different performance measures: Cohen

sKappa, sensitivity, spec if icity and Spearmans Rho. Cohen`s Kappa mesures agreement between the group-based exporsure estimates and the individual expsosure estimats, taking into account that agreement may occur by chance. According to Cohen (16) the kappa values can be classified as poor $(<0.20)$, fair $(0.21-0.40)$, moderate (0.41-0.60), good $(0.61-0.80)$ and excellent (0.81-1) agreement. Sensitivity measures the proportion of individuals who are identified as exposed based on individual estimates, that are also identified as exposed using the group-based estimates. Specificity measures the proportion of individuals who are identified as unexposed based on individual estimates, that are also identified as unexposed using the group-based estimates. Spearman

rRhomeasuresthemo $\neg$ onicrelationships, whetherl $\in$ ear or $\neg$, betweentwovariab $\leq$ s. InthispaperweuseSpearman $r$ Rho to investigate the correspondence, i.e. the rank order, between the exposures reported by the individual employee and the exposures linked to the individual using their occupational code.

As shown in Table 6, CohensKappaisfare $\rightarrow$ good and mod eratef or allexposuresexceptf or "s gave a sensitivity of $>50$ percent for six out of eight exposures. The specificity was $\geqslant 75$ percent for six out of eight exposures for men and five for women.

Table 6

Cohen`s Kappa, Sensitivity and Specificity measures

\begin{tabular}{|llllllll|}
\hline & \multicolumn{7}{c}{ Men } \\
\hline Exposures & Cut-off $\%$ & Kappa & Sensitivity & Specificity & Kappa & Sensitivity & Specificity \\
\hline Heavy lifting $(>20 \mathrm{~kg})$ & 20 & 0.37 & 82 & 66 & 0.32 & 68 & 77 \\
\hline Hands above shoulder height & 20 & 0.39 & 69 & 81 & 0.25 & 44 & 87 \\
\hline Heavy physical work & 20 & 0.31 & 76 & 70 & 0.22 & 52 & 80 \\
\hline Work with neck flexion & 20 & 0.18 & 43 & 79 & 0.16 & 51 & 70 \\
\hline Squatting/kneeling & 20 & 0.43 & 75 & 80 & 0.32 & 77 & 71 \\
\hline Forward bending & 20 & 0.24 & 45 & 87 & 0.22 & 48 & 83 \\
\hline Awkward lifting & 20 & 0.29 & 63 & 79 & 0.27 & 77 & 70 \\
\hline Standing/walking & 50 & 0.56 & 77 & 81 & 0.61 & 86 & 75 \\
\hline
\end{tabular}

Hanvold et. al. (7) used cut-off values when constructing their final Job Exposure Matrix, being as theyre goal was to investigate each exposures association with lower-back pain, our goal however is to construct a Mechanical Job Exposure Index for the use in register data analysis. Thus, we choose not to reduce the information in the exposures using cut-offs values but have instead use the exposure variables measuring the percentage within each occupational code that is exposed. The sensitivity and specificity measures provide a valuable insight into the different exposures performance in identifying exposed and non-exposed individuals. However, since our goal is to measure the overall mechanical exposure in each occupation, it seems more fruitful to consider occupations as more or less exposed based on the percentage reporting to be exposed in each occupation. Thus, we have chosen to keep the measures, measuring the percentage exposed and used in the factor analysis, as is when constructing the Mechanical Job Exposure Index (MJEI). To test the correspondence between the exposures measured as percentage exposed within each occupation (group-based exposure) and the individual reported exposures we use Spearman`s Rho, the results from a rank correlation analysis is presented in Table 7. 
Table 7

Rang correlation between exposures at the individual level and the occupational level - Spearman`s Rho

\begin{tabular}{|lll|}
\hline & Men & Women \\
\hline Composite Mechanical Job Exposure Index & .642 & .626 \\
& $(.000)$ & $(.000)$ \\
\hline Single exposures & & \\
\hline Heavy lifting $(>20 \mathrm{~kg})$ & .468 & .382 \\
\hline Hands above shoulder height & $(.000)$ & $(.000)$ \\
& .424 & .296 \\
\hline Neck flexion & $(.000)$ & $(.000)$ \\
\hline Heavy physical work & .202 & .193 \\
& $(.000)$ & $(.000)$ \\
\hline Squatting/kneeling & .394 & .380 \\
& $(.000)$ & $(.000)$ \\
\hline Forward bending & .465 & .403 \\
& $(.000)$ & $(.000)$ \\
\hline Awkward lifting & .283 & .284 \\
& $(.000)$ & $(.000)$ \\
\hline & .349 & .357 \\
& $(.000)$ & $(.000)$ \\
\hline & .600 & .637 \\
& $(.000)$ & $(.000)$ \\
\hline
\end{tabular}

The rank correlation between the Composite Mechanical Job Exposure Index based on the individual reported exposures and the group-based exposures is .642 for men and .626 for women (see Table 7). Thus, the correlation between the index based individual reported exposures and the group-based exposures is strong for both genders. For each of the eight exposures the correlation between the individual reported exposure and the group-based exposure is weak for "neck flexion" and "forward bending". Whereas the correlation is moderate for "heavy lifting", "hands above head", "Heavy physical work", "Squatting/kneeling", "Awkward lifting" and strong for "Standing/walking". When comparing the sensitivity measures with the correlations it shows that those exposures with a low sensitivity, "work with neck flexion" and "forward bending" for both genders and "hands above shoulder" for women, also have a weaker correlation. Nevertheless, an overall correlation of .642 for men and .626 for women demonstrates that the Composite Occupational Mechanical Job Exposure Index (MJEI), based on five Norwegian nationwide Survey of Living Conditions on work environment, is strongly correlated with the overall mechanical job exposures experienced at the individual level.

Low-back pain, long-term sick leave, disability benefits and mortality

To test the predictive validity of the Composite Mechanical Job Exposure Index individual reported low-back pain and long-term sick leave is used as outcome variables in the analysis based on the five surveys. Individual reported low-back pain is measured as a dummy-variable: "Have you during the last month been bothered by lower back pain?" "Very or quite bothered" = 1, "a little or not at all bothered" $=0$. Individual reported sick leave is also measured as a dummy-variable: "Have you during the last 12 months had continuous sick leave for more than 14 days?" "Yes" $=1$, "No" $=0$. 
Furthermore, the predictive validity of the Composite Mechanical Job Exposure Index is tested merging the index to register data using receipt of disability benefit in the period 2008 to 2017, the number of long-term sick leave periods between 2008 and 2015 and mortality between 2008 and 2017 as outcome variables. "Disability" and "mortality" are both measured as dummy variables: "disabled during 2008 to 2017 " = 1, "not disabled during 2008 to 2017 " = 0 and "dead during 2008 to 2015 " = 1, "not dead during 2008 to 2017 " $=0$. "Long-term sick leave periods" is measured as a continues variable and sums up the number of sick leave periods exceeding 16 days between 2008 and 2015.

Predictive validity of the Composite Mechanical Job Exposure Index

As shown in figure 1, for both men and women, the unadjusted occupational MJEl estimate is not significantly lower than the individual MJEl estimates (unadjusted and adjusted), thus the occupational MJEl shows a reproduceable likelihood for lower-back pain for men. When adjusting for level of education and age, the reproduceable likelihood for lower-back pain is significantly lower for men, but still significant.

Figure 2 shows the likelihood of reporting a long-term sick leave among men and women, according to the occupational MJEl and the individual MJEl. The occupational MJEl shows a reproduceable likelihood for long-term sick leave for both men and women, and the adjusted occupational MJEl estimate does not significantly differ from the individual estimates.

When investigating the association between the occupational MJEl and disability 2008-2017, the occupational MJEI does not predict a higher likelihood for disability among men when adjusting for age and level of education (Figure 3). For women the occupational MJEl predicts a higher likelihood for disability during 2008 to 2017 both before and after adjusting for age and level of education.

As shown in figure 4, the occupational MJEl predicts higher mortality among men both before and after adjusting for age and level of education. For women the occupational MJEl predicts higher mortality after adjusting for age and level of education.

The occupational MJEl predicts a significantly higher probability of having ten or more long-term sick leave periods during 2008 to 2015 for both men and women, before and after adjusting for age and level of education. As shown in figure 5, the predicted likelihood is almost twice as high for women compared to men.

\section{Summary, Discussion And Conclusion}

In this paper we have tested key aspects of reliability and validity for a composite measure of a mechanical job exposure matrix, MJEI. Our main findings may be summarized in the following three points. 1) A confirmatory factor analysis shows that the 8 items measuring different aspects of mechanical exposures reflects one underlying dimension, and thus indicates that the index MJEI is reliable. 2) The overall rank order correlation (Spearman's Rho) between individual and occupation based mechanical exposure is moderate-high and suggests that MJEl can be used when individual exposures are not available. 3) An analysis of the predictive validity of the MJEl suggests that overall the constructed MJEl index is related to several health outcomes in the expected way. This analysis was carried out on survey data and register data and involved health outcomes like self-reported back pain, long term sick leave, receipt of disability benefit and mortality. The validity of MJEI thus seems to be acceptable.

As alluded to above, the JEM approach has some weaknesses related to imprecision as compared with individually reported exposures. The reliability and validity tests carried out in this article suggest, however, that its statistical properties altogether are fair. One should also be aware of one advantage that JEM has as compared with a heavily debated problem pertaining to selfreported job exposures, namely systematic reporting bias (17). Using JEM, one can to a large extent ignore this possible problem.

A strength of this study is the high number of observations that is achieved by merging five waves of The Survey of Living Conditions. This has resulted in 43977 valid respondents. The mean number of respondents in each JEM group is 412 and the median is 261 . The largest JEM group include 1503 respondents and the smallest 19 respondents. Only two JEM groups have the minimum number of 19 respondents. Overall, these high numbers increase the precision of the estimated exposures of mechanical al hazards. As pointed out by Choi (18) there might be a trade off between number of subjects in each JEM group and the precision of the estimated exposures: To collapse several occupational groups in order to obtain a higher number of observations, will to 
some extent result in lower precision. In our material, this is less of a problem since few occupations are collapsed and the remaining are "clean" occupational groups.

The validation literature referred to above seems to conclude that when individual information on job exposures is lacking, JEM is a useful proxy. Our results seem to confirm this body of research. The statistical properties of our mechanical job exposure index (MJEI) are overall acceptable. Since it was our purpose to construct a JEM index that could be used in analyses of register data, we are inclined to conclude that MJEl is a valid measure of mechanical exposures that can be informative in register-based studies in Norway.

\section{Abbreviations}

STYRK-98: Standard for occupational classification used from 1998

STYRK-08: Standard for occupational classification used from 2008

JEM: Job Exposure Matrix

MJEl: Mechanical Job Exposure Index

p: Probaility

CFA: Confirmative factor analysis

RMSEA: Root mean square error of approximation

CFI: comparative fit index

TLI: Tucker-Lewis index

SRMR: standardised root mean square residual

\section{Declarations}

\section{Ethics approval and consent to participate}

The data used in this paper has been collected by Statistics Norway (SSB) and research conducted has been approved by the Norwegian Data Protection Official for Research (NSD) and The Norwegian Data Protection Authority (Datatilsynet). Thus, the ethical and legal aspects of this research have been thoroughly evaluated.

\section{Consent for publication}

Not applicable.

\section{Availability of data and materials}

The authors do not have the right to share any data information as per their institutions policies.

\section{Competing interests}

The authors have no conflicts of interest to report.

\section{Acknowledgements}


Not applicable.

\section{Funding}

The study has been funded by WELLIFE (projectnumber NordForsk 83540) and INTEGRATE (projectnumber NFR 269298).

\section{Author information}

\section{Faculty of Social Sciences, Department of Social Work, Child Welfare and Social Policy, Oslo, Norway}

Åsmund Hermansen

Faculty of Social Sciences, Department of Social Work, Child Welfare and Social Policy, Oslo, Norway

Espen Dahl

\section{Authors' contributions}

$\AA ̊ H$ and ED developed the design of the study and $\AA \mathrm{H}$ completed the statistical analysis and made the first draft. ÅH and ED were both involved in finishing the manuscript, interpretation of the results and revising it critically for important intellectual content. Both authors read and approved the final manuscript.

\section{References}

1. Wel KA van der, Östergren O, Lundberg O, Korhonen K, Martikainen P, Andersen Nybo A-M, Urhoj Kjaer S. A gold mine, but still no Klondike: Nordic register data in health inequalities research. Scandinavian Journal of Public Health. 2019; 47(6):618-630 doi: $10.1177 / 1403494819858046$

2. Blossfeld H-P Evidence of Causation-The Contribution of Life Course Research, Part I: Dominant Models of Causal Inference and Their Limitations in Life Course Research. Emerging Trends in the Social and Behavioral Sciences. 2017; 1-20. ISBN 978-1118-90077-2.

3. Ben-Shlomo Y. og Kuh D. A life course approach to chronic disease epidemiology: conceptual models, empirical challenges and interdisciplinary perspectives. International Journal of Epidemiology. 2002; 31, 2, 285-293.

4. Milner A, Niedhammer I, Chastang J-F, Spittal MJ, LaMontagne AD. Validity of a Job Exposure Matrix for Psychosocial Job Stressors: Results from the Household Income and Labour Dynamics in Australia Survey. PLoS ONE. 2016; 11(4): e0152980. doi:10.1371/journal.pone.0152980

5. Solovieva S, Pehkonen I, Kausto J, Miranda H, Shiri R, Kauppinen T, et al. Development and Validation of a Job Exposure Matrix for Physical Risk Factors in Low Back Pain. PLoS ONE. 2012; 7(11): e48680 https://doi.org/10.1371/ journal.pone. 0048680

6. Kauppinen, T. Uuksulainen, S. Saalo, A, Mäkinen, I. Pukkala, E. Use of the Finnish Information System on Occupational Exposure (FINJEM) in Epidemiologic, Surveillance, and Other Applications. The Annals of Occupational Hygiene. 2014; 58, 3 , 380-396, https://doi.org/10.1093/annhyg/met074

7. Hanvold TN, Sterud T, Kristensen P, Mehlum IS. Mechanical and psychosocial work exposures: the construction and evaluation of a gender-specific job exposure matrix (JEM). Scand J Work Environ Health. 2019; 45(3):239-247. doi: 10.5271/sjweh.3774.

8. BongKyoo Choi. Developing a Job Exposure Matrix of Work Organization Hazards in the United States: A Review on Methodological Issues and Research Protocol Safety and Health at Work. 2020, 11 397e404

9. Garcia A. Galarzo, MCG, Alba, MA. Gordo J. et al. A job-exposure matrix for Spanish workers. Seguridad y Medio Ambiente. 2011, 31, 123.

10. Rijs KJ, van der Pas S, Geuskens GA, Cozijnsen R, Koppes LL, van der Beek AJ, Deeg DJ. Development and validation of a physical and psychosocial job-exposure matrix in older and retired workers. Ann Occup Hyg. 2014 Mar;58(2):152-70. doi: 10.1093/annhyg/met052 
11. Le Moual N, Bakke P, Orlowski E, Heederik D, Kromhout H, Kennedy S M, Rijcken B, Kauffmann F. Performance of population specific job exposure matrices (JEMs): European collaborative analyses on occupational risk factors for chronic obstructive pulmonary disease with job exposure matrices (ECOJEM). Occupational and Environmental Medicine. 2000;57:126-132

12. Örhede E. Nordic cooperation in research on work environment. Scand J Work Environ Health 1994;20(1):65-66 doi:10.5271/sjweh.1426

13. Sterud T and Tynes T. Work-related psychosocial and mechanical risk factors for low back pain: a 3-year follow-up study of the general working population in Norway Occup Environ Med. 2013;70(5):296-302. doi: 10.1136/oemed-2012-101116.

14. Browne $M$ and Cudeck R. Alternative ways of assessing model fit. In: Bollen $\mathrm{K}$ and Long $\mathrm{J}$ (eds) Testing structural equation models. London: Sage, 1993.

15. Hu L and Bentler P. Cutoff criteria for fit indexes in covariance structure analysis: conventional criteria versus new alternatives. Struct Equ Modeling. 1999;6:1-55.

16. Cohen J. Weighted kappa: nominal scale agreement with provision for scaled disagreement or partial credit. Psychol Bull. 1968; 70(4):213-20. https//doi.org/10.1037/h0026256.

17. Stock SR, Fernandes R, Delisle A, Vézina N. Reproducibility and validity of workers' self-reports of physical work demands. Scand J Work Environ Health. 2005; 31(6):409-37. https://doi.org/10.5271/sjweh.947.

18. Choi, BK. Determining an optimal minimum number of subjects in each occupation for a job exposure matrix (JEM) using selfreported data: a missing test. Scand J Work Environ Health. 2019;45(4):421-422.

\section{Figures}
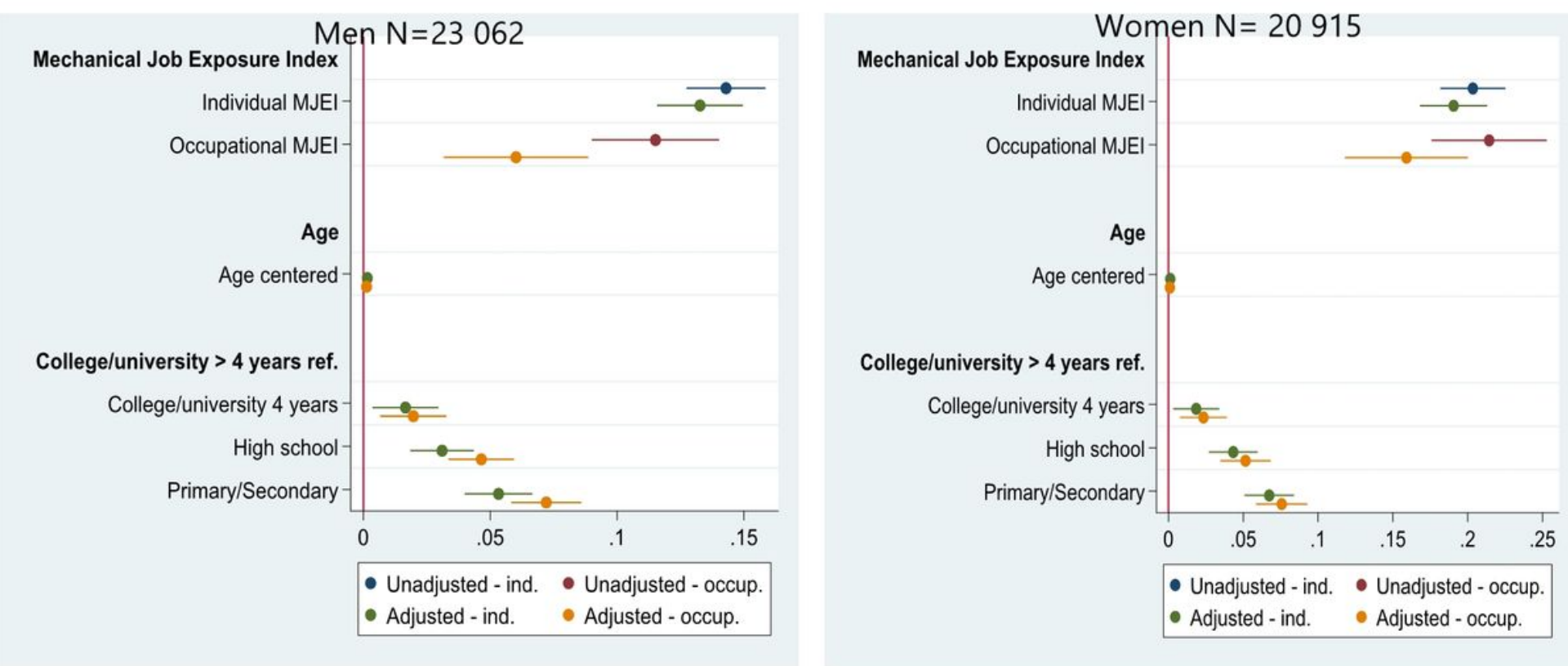

\section{Figure 1}

Linear probability model using survey data only and individual reported lower-back pain as dependent variable. Results when not adjusting and adjusting for level of education and age. 
Men $\mathrm{N}=23062$

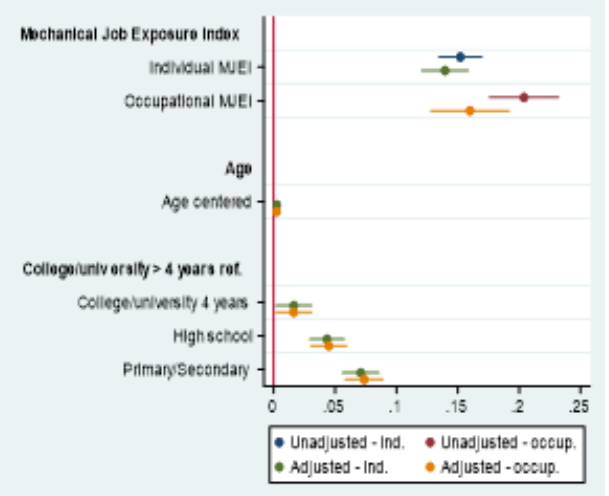

Women $\mathrm{N}=20915$

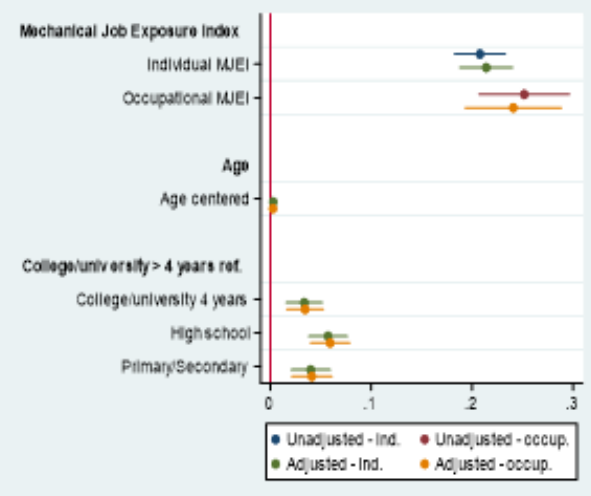

\section{Figure 2}

Linear probability model using survey data only and individual reported long-term sick leave as dependent variable. Results when not adjusting and adjusting for level of education and age.

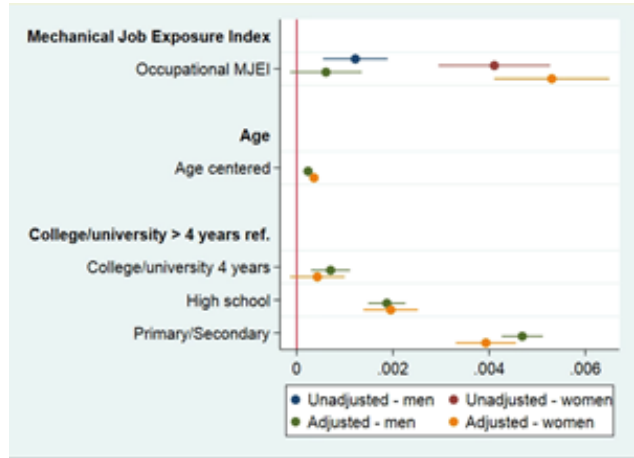

\section{Figure 3}

Linear probability model using disability 2008-2017 as dependent variable. Results when not adjusting and adjusting for level of education and age. Register data. Men N=819 232. Women N=770 303.

\section{Figure 4}

Linear probability model using mortality 2008-2017 as dependent variable. Results when not adjusting and adjusting for level of education and age. Register data. Men N=819 232. Women N=770 303.

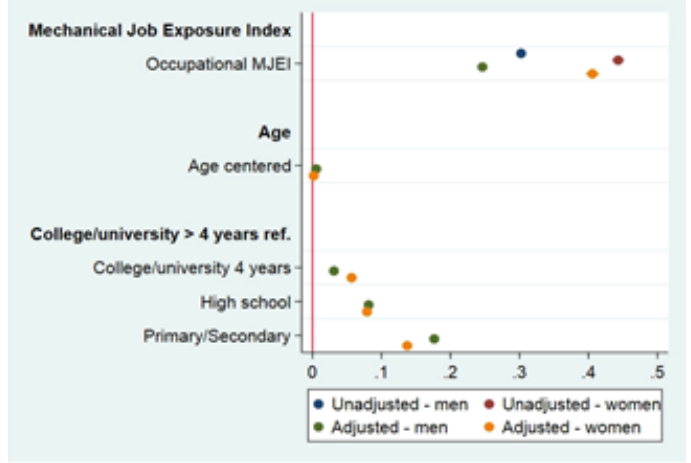

Figure 5 
Linear probability model using ten or more long-term sick leave periods $2008-2015$ as dependent variable. Results when not adjusting and adjusting level of education and age. Register data. Men N=819 232. Women N=770 303. 